صخارية ومراحل نشأة نطاق الارض الصلبة في اعلى الجزء العلوي لتكوين بخمة، منطقة دهوك، شمالي العرلق

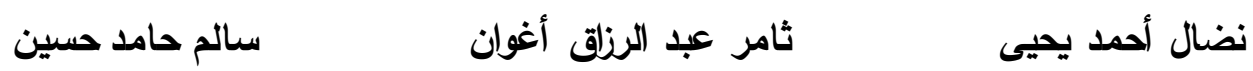

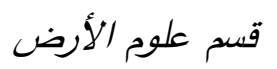

$$
\begin{aligned}
& \text { كلية العلوم } \\
& \text { جامعة الموصل }
\end{aligned}
$$$$
\text { (تاريخ الاستلام 2014/1/7 تاريخ القبول 2014/3/24) }
$$

\title{
الملخص
}

يقع نطاق الارض الصـلبة في اعلى الجزء العلوي لتكوين بخمة في منطقة دهوك، وتتألف صـــخوره من

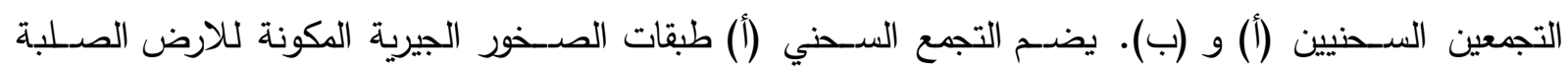

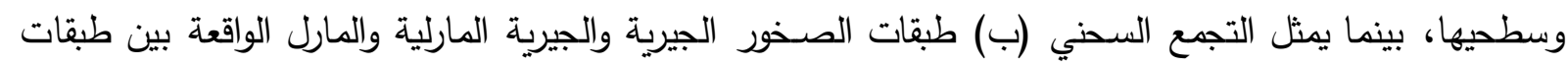

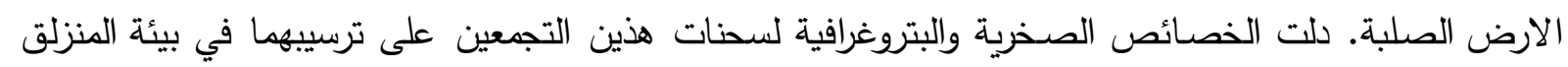

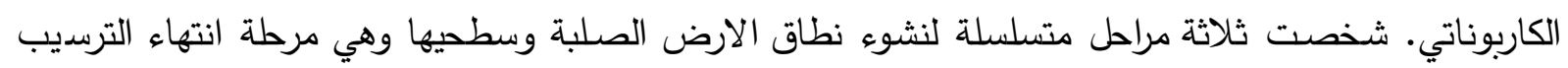

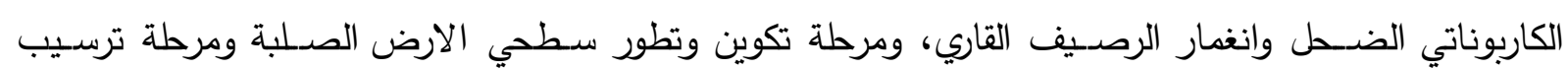

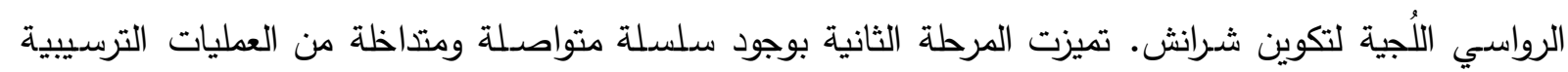

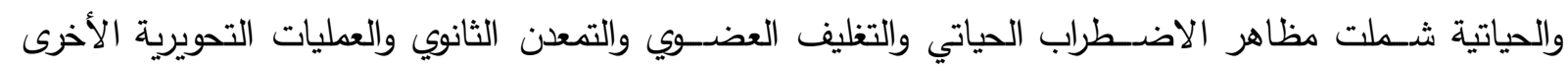

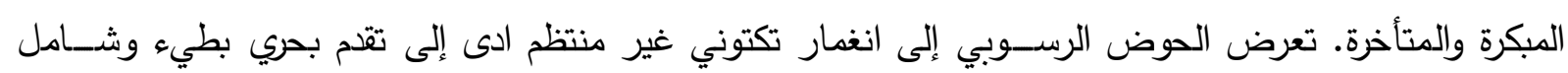

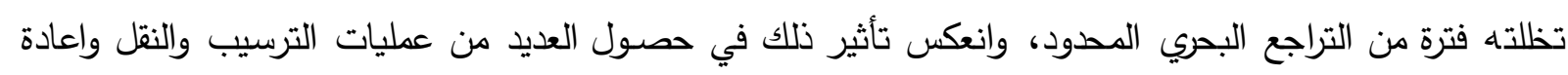

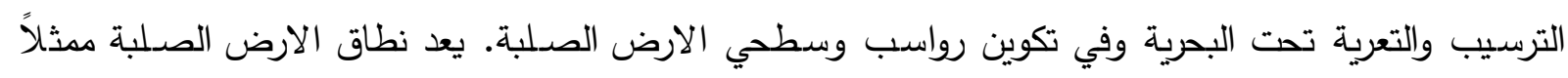
لعدم توافق انغماري ما بين تكويني بخمة وشرانش خلال الفترة المحصورة ما بين الكامبانيان والماسترختيان. الكلمات الدالة: الارض الصلبة، منطقة دهوك، تكوين بخمة، المنزلق الكاربوناتي، عدم توافق انغماري.

\section{Petrology and Genesis Development of the Hardground at the Uppermost Part of Bekhme Formation, Dohuk Area, Northern Iraq}

\author{
Nidhal A. Yahya \\ Thamer A. Aghwan \\ Salim H. Hussain \\ Department of Geology, \\ College of Science, \\ University of Mosul
}




\section{ABSTRACT}

Hard ground at the uppermost part of Bekhme Formation is studied at three outcrop sections located in the Dohuk area, northern Iraq, and it is found that it consists of two distinct facies associations. The first includes limestone beds that comprise the hard ground and its omission surfaces. The second consists of limestone, marly limestone, and marl, which is interbedded with successive hard ground. The overall characters of these two facies associations indicate that deposition took place in a carbonate ramp setting. Vertical variations of sedimentary components suggest that the hard ground was developed by three successive stages. These are the end of shallow carbonate sedimentation and the drowning of the platform, the formation and modification of hard grounds, and finally the deposition of pelagic carbonate sediments of the Shiranish Formation.

The second stage is characterized by intercalations of continuous depositional and biological processes. These include bioturbation, bioencrustation, and secondary mineralization in addition to other early and late diagenetic processes. The depositional area had been affected by tectonic drowning of carbonate ramp with a wide gradual marine transgression associated with a period of local marine regression that is, in turn, responsible for deposition, transportation, redeposition, submarine erosion and formation of hard grounds. Thus, the hard ground zone represents drowning unconformity surfaces between Bekhme and Shiranish formations through the Campanian- Maastrichtian boundary.

Keywords: Hard ground, Dohuk area, Bekhme Formation, Carbonate ramp, drowning unconformity.

\section{المقدمة}

تتشكل طبقات الارض الصـلبة (Hardground) من التصـلب البطيء للرواسـب الجيرية المترسبة في قيعان البحار عند مواقع التقاء سـطح الرواسـب بمياه البحر (Bathurst, 1975). تؤدي هذه العملية إلى تكوين السطوح المتروكة (omission surfaces) أو سطوح عدم الاستمرارية (discontinuity surfaces) التي تشكل التعل حدوداً حادة تفصـل بين الدـحنات الرسـوبية المختلفة اعتماداً على الادلة الرسـوبية وهندسية الطبقات والعمليات التحويرية والطباقية الحياتية مما يشـير إلى حصــول توقف في الترسـيب (Chari et al., 1995). يتقق معظم الباحثين على ان هذه السطوح تمثل فترة زمنية مفقودة (hiatus) بين الطبقات الرسوبية الواقعة فوقها وتحتها. تثــير الـدراســـات الســـابقـة إلى ان سـطوح الارض الصدـلبـة تمثل حداً فـاصدــلاً بين تكويني بخمة (Bekhme Formation) وشـرانش (Shiranish Formation)، ويعد ( Wetzel, 1950; In) (Bellen et al., 1959 المنخربات الطافية (Condensed planktonic forminifera)، وزيادة في نســبة معدن الكلوكونايت. كذلك اشسارت دراسة كل من (Al-Mutwali et al., 2008) و (الشريدة، 2009) لتكوين بخمة في منطقة دهوك إلى وجود طبقتين من الارض الصلبة في جزئه العلوي. 


\section{موقع منطقة الدراسة والوضع الجيولوجي}

تقع منطقة الدراسـة ضــمن طية بيخير المحدبة (Bekhair Anticline) الواقعة في نطاق الطيات العالية وتبعد هذه الطية حوالي 6 كيلومترات إلى الشمال الثرقي من مدينة دهوك، تتكثف في (High Folded Zone) هذه الطية الصخور التي تمتد اعمارها من الكريتاسي العلوي (Upper Cretaceous) إلى النيوجين (Neogene)

والتي تتمثل من الاقدم إلى الاحث بتكوينات بخمة، شرانش، كولوش، جركس، أفانه، بيلاسبي، فتحة وانجانة. اشتملت الدراسة الحالية على المنكثفات الصخرية لنطاق الارض الصلبة الواقعة بين اعلى تتابعات تكوين بخمة وأسفل تتابعات تكوين شرانش، وتتراوح اعمارها ما بين الكامبانيان المتأخر والماسترختيان المبكر، تم اختيار ثلاثة مكاشف صخرية هي مقطع وادي كرماوة (الموقع L1) ومقطع الجناح الجنوبي (الموقع L2) ومقطع الجناح الشمالي للطية (الموقع L3) (الشكل 1).

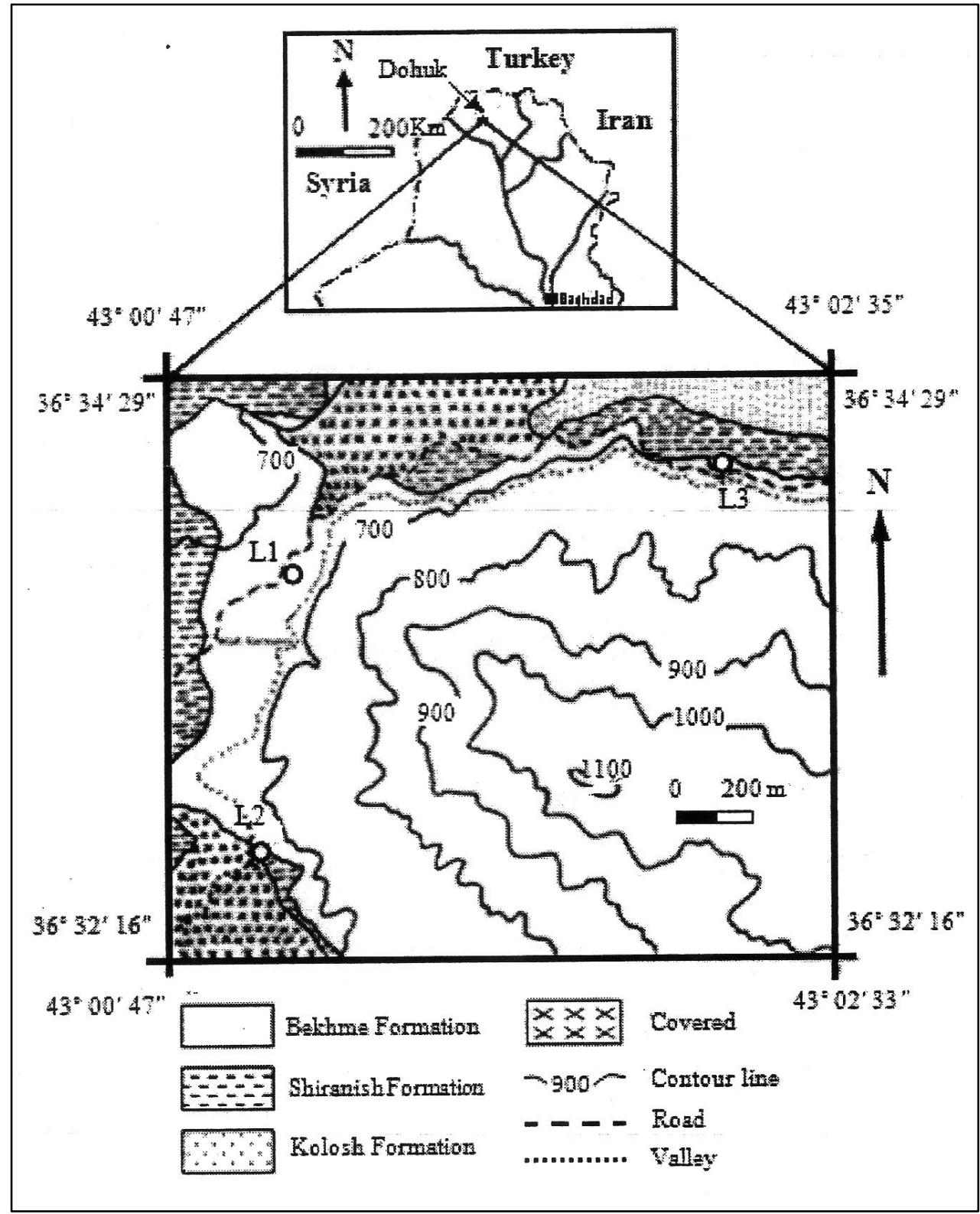

الثكل 1 : خارطة جيولوجية تبين مواقع مقاطع الدراسة (عن الثريدة، 2009) 


\section{طرائق وأهداف الدراسة}

تضمن العمل الحقلي الوصف الصـاري لنطاق الارض الصلبة ومتابعة تغيراتها العمودية والجانبية فضـلاً عن دراسـة التراكب الرسـوبية الفيزيائية والحياتية. اختير (30) انموذجاً صدخرياً للدراسـة الحالية، وتمت معاملة الفيلة شـرائحها الرقيقة بصــبغتي الاليزارين الحمراء وسـيانيد البوتاسـيوم الحديدي وفقاً لطريقة (Bickson, 1966). استخدم تصدنيف فولك (Folk, 1962) في التطيل السـني ووصدف الانسـجة الصـخرية لتعلقه بالاعتبارات المنثأية والبيئية للصخور الجيرية. يهدف البحث الحالي إلى اجراء دراسـة تفصديلية للطبيعة الصدخرية والســنية لسـوح وطبقات الارض الصـلبة وتشخيص كافة الظواهر الرسوبية المميزة لها وتقسير طريقة تكوينها ومراحل نشـوئها ومن ثم مناقشـة علاقتها بالبيئة الترسيبية والعوامل المسيطرة عليها.

\section{الصخارية والتحليل السحني}

تتألف الطبقات الواقعة في اقصدسى الجزء العلوي لتكوين بخمة من طبقتين من الارض الصدـلبة تمتاز صخورها بصلادتها العالية وتظهر كأضلاع بارزة (Ridges) بسك يتراوح بين (0.5- 2.6 م) تنتهي في الاجزاء العليا منها بسطوح الارض الصـلبة. كذلك توجد بين هاتين الطبقتين تتابعات لصـخور أقل صدـلادة من سـابقتها يصل سمكها إلى (4 م) (الشكلان 2 و3). واستناداً إلى التغاير في الخصـائص الصدخية والنسيجية وطبيعة التراكيب الرسـوبية ومظاهر الاثار الحياتية (Trace fossils) أمكن تقسيم نطاق الارض الصـلبة إلى تجمعين سحنيين (Facies associations) هما: 1- التجمع السحني (أ) (ت س.أ):

يمثل هذا التجمع طبقتي الارض الصلبة وسطحيها، ويتألف بشكل رئيس من الصخور الجيرية بحجم الرمل غنية بالمستحثات (Biocalcarenite)، مع وجود بعض التداخلات من الصـخور الجيرية بحجم الحصسى والطين (Calcirudite and calcilutite)

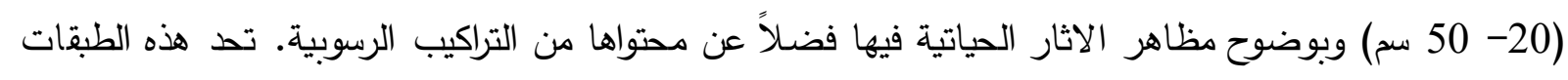

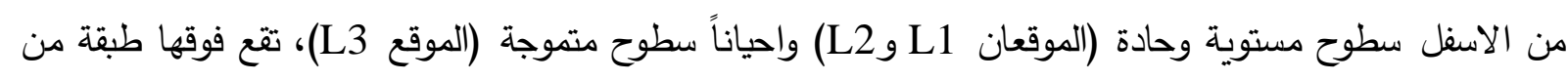

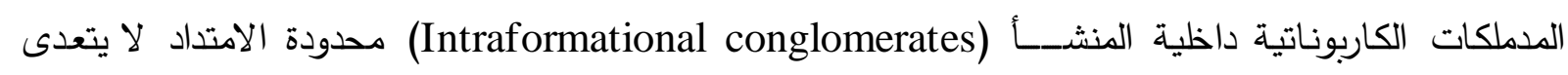
سمكها (40 سم) (الثكل 3).

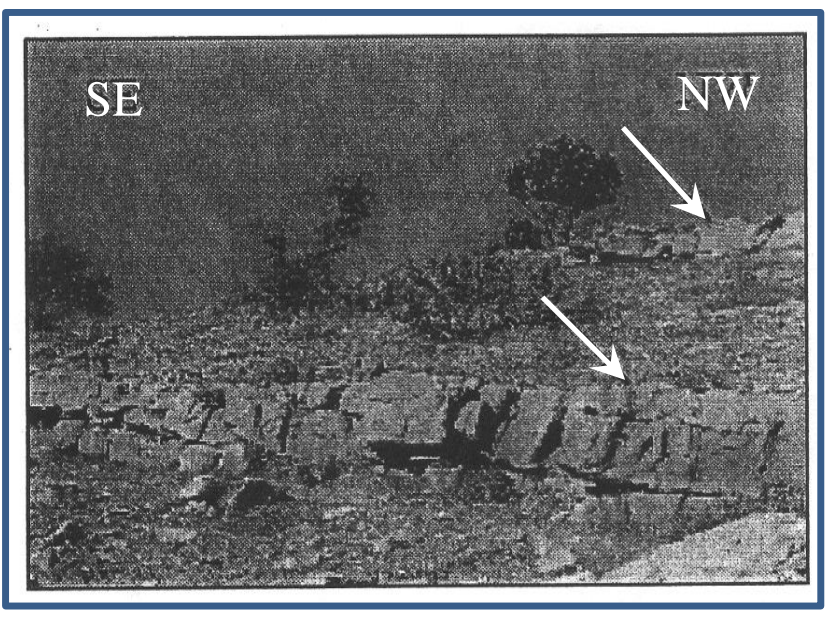

الثكل 2: طبقات الازض الصلبة (الاسهم) في

الجناح الثمالي لطية بيخير (الهوقع L33). 


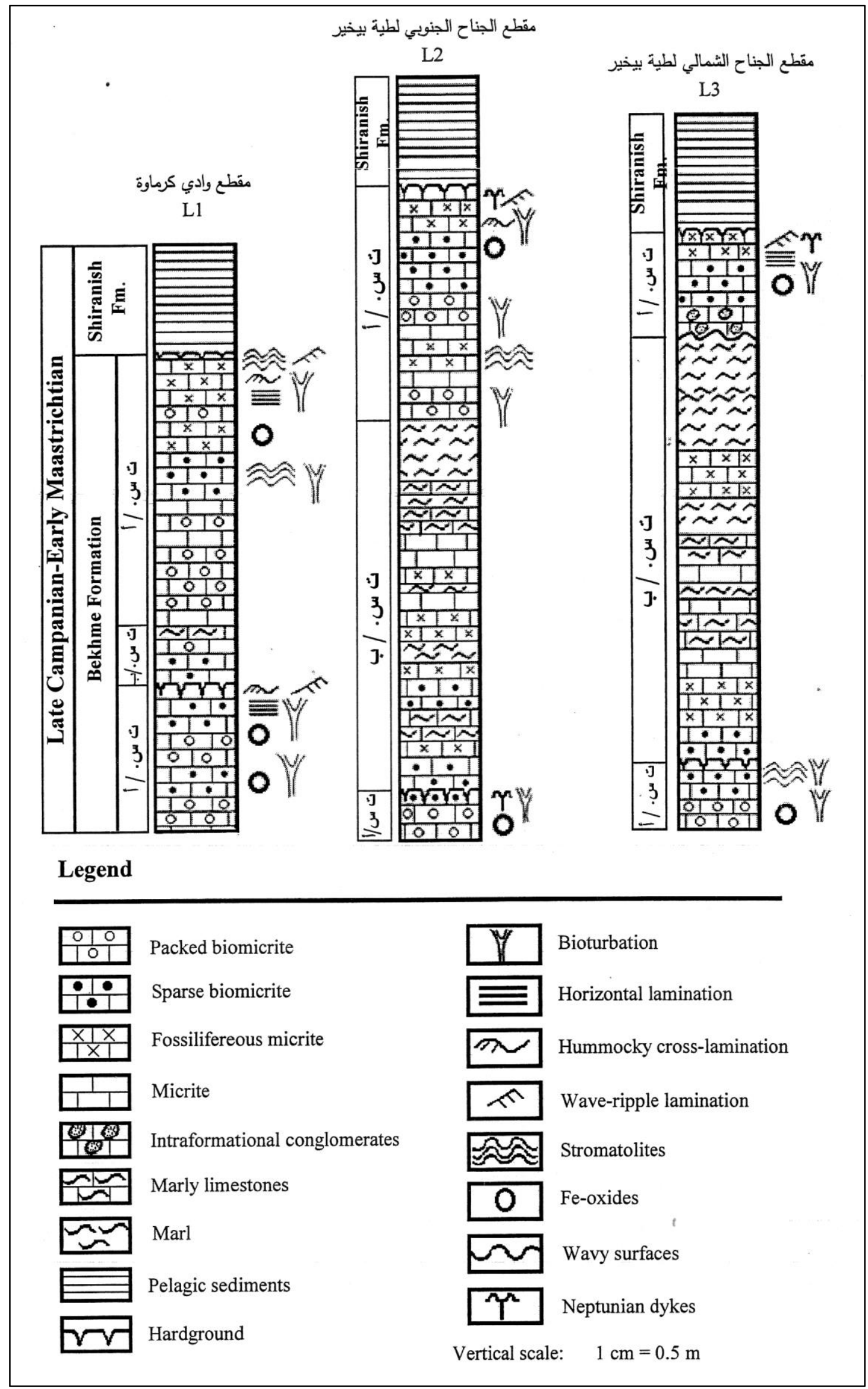

الثكل 3: المقاطع الصخرية لنطاق الارض الصلبة في اعلى الجزء العلوي لتكوين بخمة 
تحتوي صد-خور هذا التجمع في بعض الأماكن على تراكيب الترقق الأفقي (-) (parallel lamination) التي تتدرج نحو الأعلى إلى الترقق النيمي المتقاطع (- Wave - ripple cross lamination) و / و أو إلى تطبق الروابي المتقاطع (hummocky cross - bedding) (الثــكل 4). وينتهي هذا التتابع أحيانا بعلامات

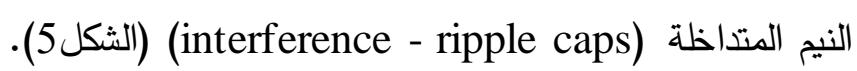

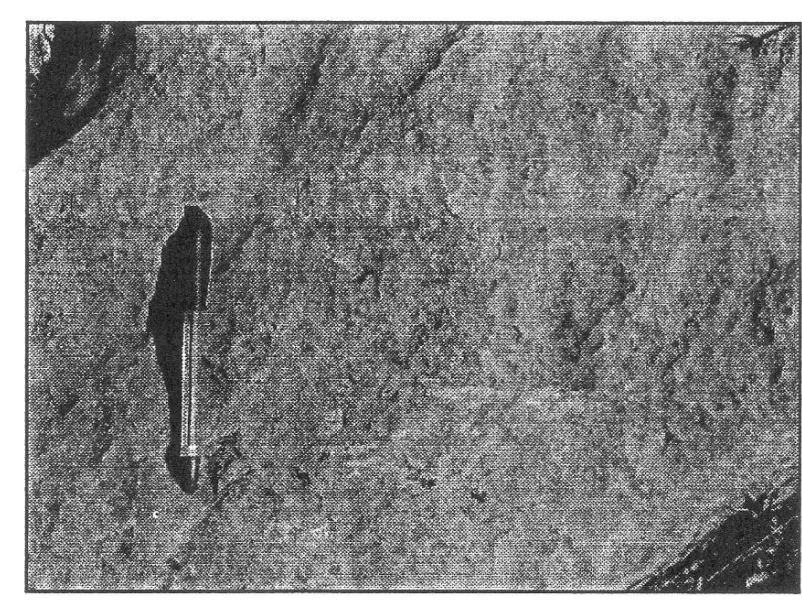

الثكل 5: علامات النيم المتداخلة على سطح صخور التجمع السحني أ في مقطع وادي كرماوة (الموقع L1)

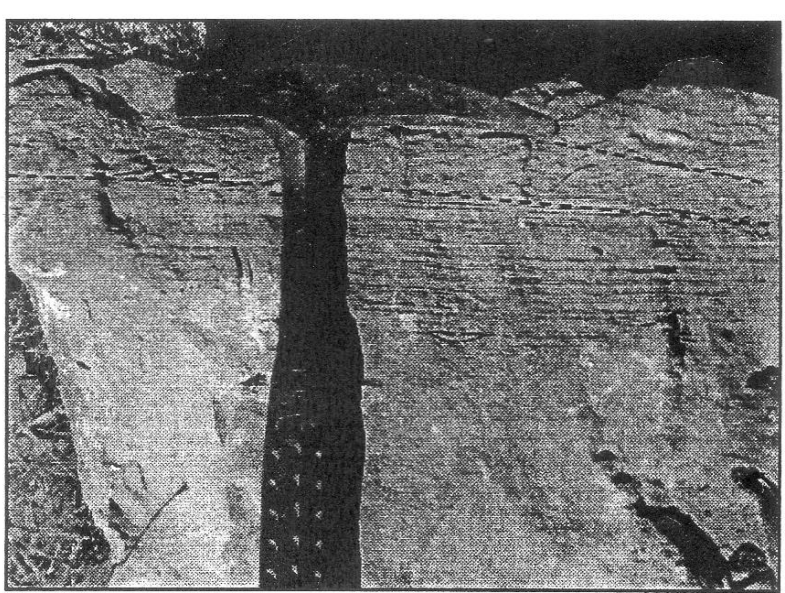

الثكل 4: تراكيب الترقق الأفقي يتدرج نحو الاعلى إلى تراكيب الترقق النيمي المتقاطع لصخور التجمع السحني ألتئي في الجناح الجنوبي لطية بيخير (الموقع L2)

foraminiferal ) تتكون سحنات هذا التجمع بشكل رئيس من سحة المكرايت الأحاثي الحاملة للمنخربات

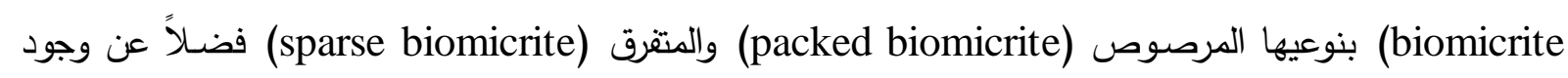
نسبة قليلة من سـحنة المكريت شـحيح المستحاثات (fossilifereous micrite). تتالف الحبيبات الكاربوناتية

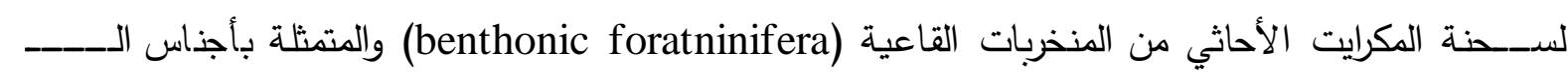

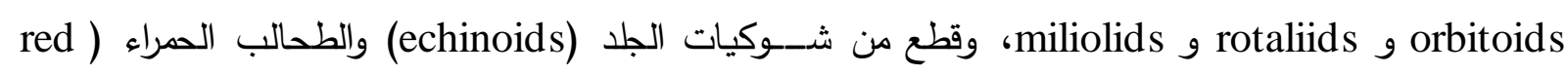
(algae والنواعم (mollusks) ونسبة قليلة من المنخربات الطافية والمكسرات الحياتية (bioclasts) (لوحة 1 -

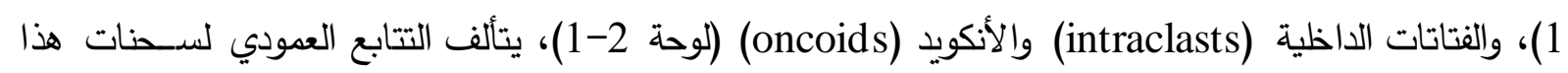
التجمع من تعاقب دوري متبادل ما بين سحنتي المكرايت الأحاثي المرصدص والمكرايت الأحاثي المتفرق يتذاخل معهما أو تعلوهما سحنة المكرايت شحيح المستحاثات (الشكل 3)، كذلك تتصف سحنات هذا التجمع (رغم التتوع الثديد في مكوناتها النسيجية) بوجود زيادة في نسبة المنخربات القاعية الكبيرة في أجزائها السفلية مقارنة مع ازدياد

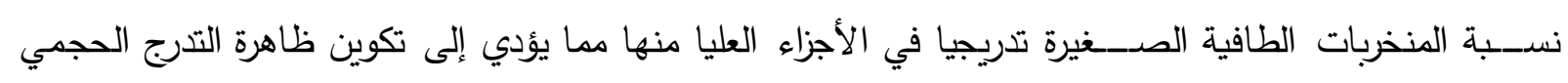
المتنعم نحو الأعلى (fining upward sequence). تدل المواصدفات السحنية والصدخرية لهذا التجمع وأطوار التعاقب العمودي للتراكيب الرسوبية على تأثرها بالعواصف والأمواج البحرية خلا فترات نشوئها، وبذلك تكون مواصفات هذا التجمع السحني مماثلة لمواصفات

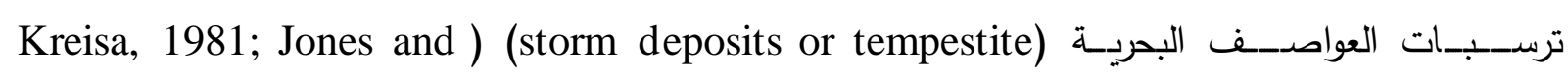
تُرسئ 2001 
المنزلق الكاربوناتي الداخلي والأوسط (inner to middle carbonate ramp) ذي الطاقة العالية من افضـل المواقع البيئية الممثلة لهذه الترسبات وذلك للتشـابه الكبير في خصـائص رواسـب هذه السدحنة مع رواسـب هذا

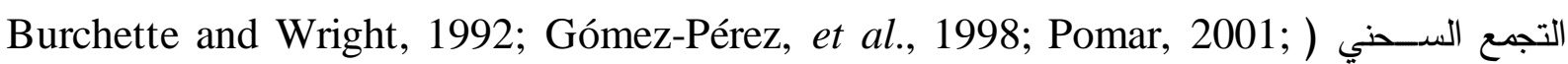

.(Bádenas et al., 2005

$$
2 \text { - التجمع السحني (ب) (ت س.ب): }
$$

تتألف طبقات هذا التجمع من الصدـخور الجيريـة بحم الرمل والطين ومن الصـــخور الجيرية المارلية وصخور المارل الواقعة بين طبقتي الأرض الصلبة (ت س ـ أ) ويتغير سككها الكلي في مقاطع الدراسة، إذ يتراوح بين 55 سـم في الموقع L1 ليصـل إلى 3.4 و 4 م في الموقعين L2 و L3 على التوالي (الثشكلان 2 و 3). تمتاز معظم صدـخور هذا التجمع بطبقاتها الرقيقة التي يبلغ معدل سـمكها 10 سدم، وتكون بعض هذه هذه الطبقات محاطة بسطوح مستوية وبعضها الأخر بسطوح متموجة تسببت في ظهورها بهيئة عقدية والتي ربما تعزى لتأثرها بعمليات الاتضغاط.

تتصف السحنات الدقيقة للصخور الجيرية وبعض الصخور الجيرية المارلية بتجانسها العالي وتتألف بشكل رئيس من المكريت الأحاثي المتفرق والمكرايت شــحيح المسـتـحاثات ونســبة قليلة من المكرايت، وتتدرج هذه السحنات في الغالب باتجاه أعلى التجمع إلى صخور المارل الذي قد يتداخل أحياناً بين صخور هذه السحنات مما يدل عموما على التتعم باتجاه الأعلى (الثدكل 3). تتكون الحبيبات الكاربوناتية بصدورة رئيسـة من مسدتحاثات المنخربات الطافية وقطع شـوكيات الجلد مع وجود نسـب قليلة من المنخربات القاعية الصدـيرة الحجم والنواعم

$$
\text { والمكسرات الحياتية (لوحة } 1 \text { - 3). }
$$

اتسـمت سـحنات هذا التجمع بخلوها من التراكيب الرسـوبية الدالة على الطاقة العالية وبغزارة المنخربات الطافية التي تصل أحيانا إلى مستوى التكثيف (لوحة 1 - 4) فضلا عن ندرة تأثرها بمظاهر الاضطراب الحياتي. Burchette and Wright, ) (deep ramp) تتشـابه مجمل هذه المواصـفات مع ترسبات بيئة المنزلق العميق 1992; Gómez-Pérez, et al., 1998; Badenas et al., 2005 الخارجي (outer carbonate ramp) ذي الطاقة الهيئة نسبياً.

\section{مراحل نشوء نطاق الأرض الصلبة}

تعكس سطوح الأرض الصـلبة والتغير السـحني للصـخور الواقعة فوقها وتحتها في الدراسـة الحالية وجود ثلاثة مراحل منشأية متسلسلة، وفيما يأتي وصف لهذه وحند المراحل (الشكل 6): 1 - مرحلة انتهاء الترسيب الكاربوناتي الضحل وانغمار الرصيف القاري: اقترحت عدة طرق لتفسير اسباب انغمار (drowning) الأرصفة القارية، أهمها الارتفاع المفاجئ لكستوى

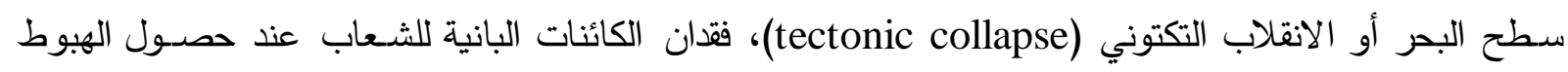
للمنصـات الكاربوناتية، وتعكر أو تلوث المياه بالمواد الفتاتية و/أو المواد البركانية، أو حصول طغيان للمياه الغنية بالمواد الغذائية مسببة نقصسان مضطرد في جهد النمو (Clari et al., 1995). ترجح الدراسة الحالية ميكانيكية الانقلاب التكتوني المصاحب لارتفاع مستوى سطح البحر بكونه سبباً رئيساً لانغمار الرصيف القاري (الشكل 6- 
و وذلك بدليل تغير النظام البيئي عند حدود سطوح الأرض الصلبة من بيئة الأرصفة القارية إلى البيئة العميقة

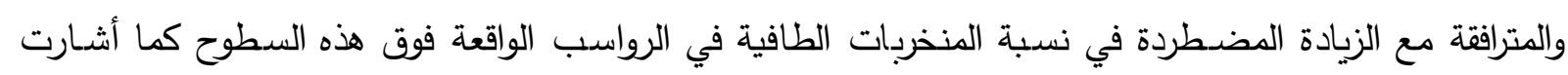
إلى نلك العديد من الدراسات (Winterer and Bosellini, 1981; Read, 1985; Clari et al., 1995).

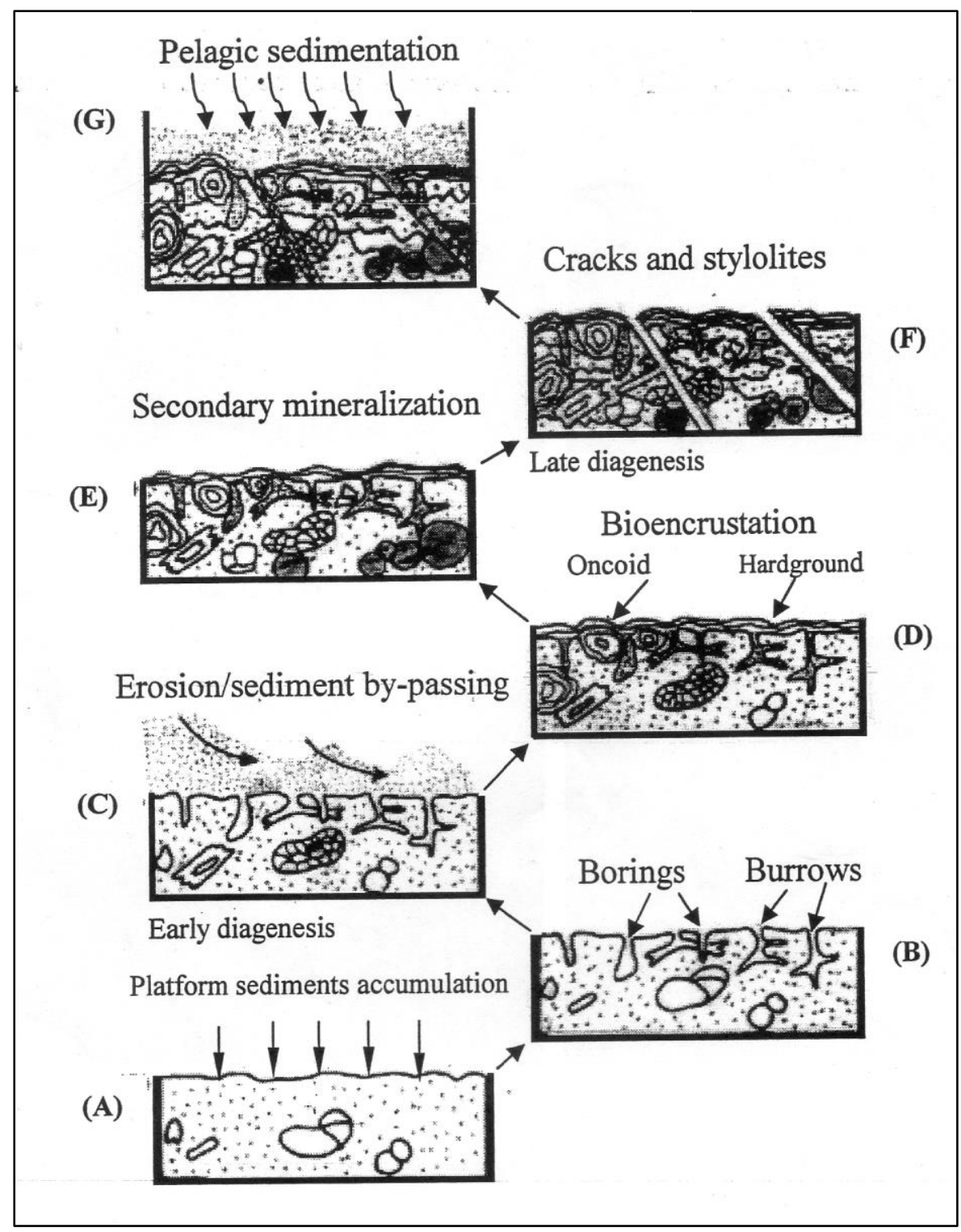

الثكل 6: مراحل نشوء وتطور نطاق الارض الصلبة

2- مرحلة تكوين وتطور نطاق الأرض الصلبة:

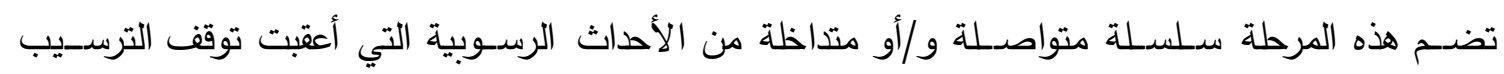

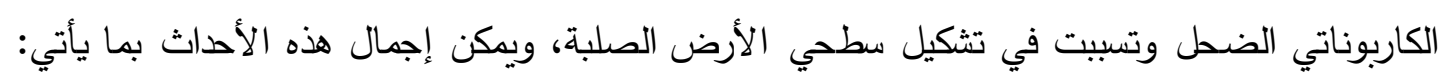
أ- مظاهر الاضطراب والتعرية الحياتية (bioturbation and bioerosion): تثــمل آثار الحفر (borrowing) والتثقيب (boring) التي انعكس تأثيرها على الســطوح الدتروكة والترسبات المرافقة لها (الثكل 6 - B ). يظهر تأثير حفر الأحياء بهيئة تثكيلات شبكية متفرعة أو بهيئة دهاليز 
شــبـ أفقية تتراوح أقطارهـا بين 2-7 ســم. وتعود هذه الحفر إلى المســتحاثات الاثاريـة للا (galleries) Thalassinoides

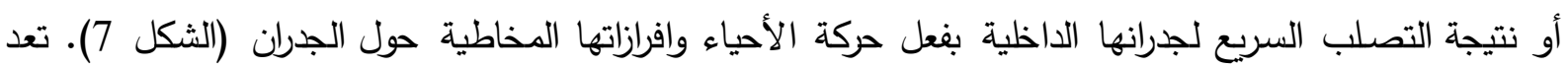
هذه الحفر جزءا من المستحاثات الأثارية العائدة إلى مجموعة الـ Gruziana المنتشرة في رواسب القيمان البحرية Bromley, 1975; Reolid et al., ) الهشـة والمتصـلبة ضــمن البيئات ذات الطاقة الواطئة إلى المتوسـطـة

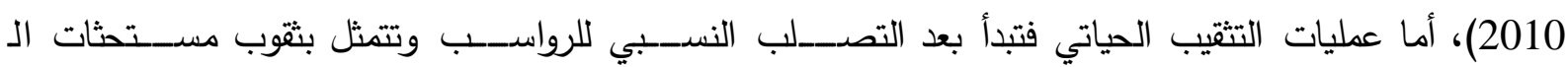

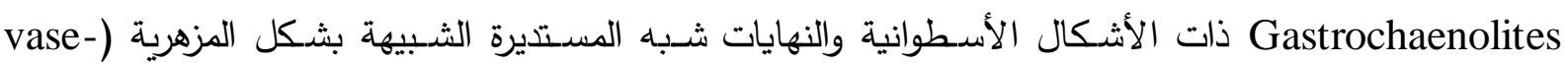

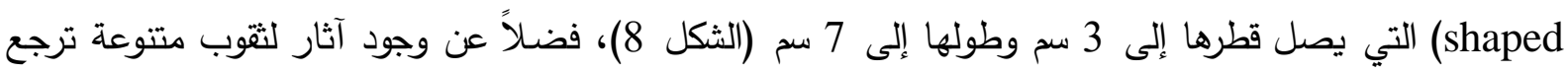
عائدية معظمها إلى الديدان البحرية التي تتركز على أسطح الطبقات (الشكل 9) أو تخترقها بشكل عمودي (لوحة .$(5-1$

تعد الوفرة والتركيز العالي لحفر وثقوب الأحياء وكثرة تواردهما معا دليلا على التناقص المفاجئ في معدل Bromley, 1975; Chacón and Martin-Chivelet, ) سرعة الترسيب والتعاقب المستمر لتصلب القيعان الماك)، (2008; Grádinaru et al., 2011 التراكيب العقدية (nodular structures) (الث_كل 7) أو التراكيب المبقعة (mottled structures) (الثـكل الثل 10). تتألف هذه التراكيب من بقع أو حبيبات من المكرايت الداكن اللون ضمن أرضية من المكرايت الفاتح اللون، وربما تعزى الألوان الداكنة لهذه التراكيب إلى الازدياد الملحوظ في نسـبة المادة العضــوية في بيئة عميقة نسـبياً

.(Grádinaru et al., 2011)

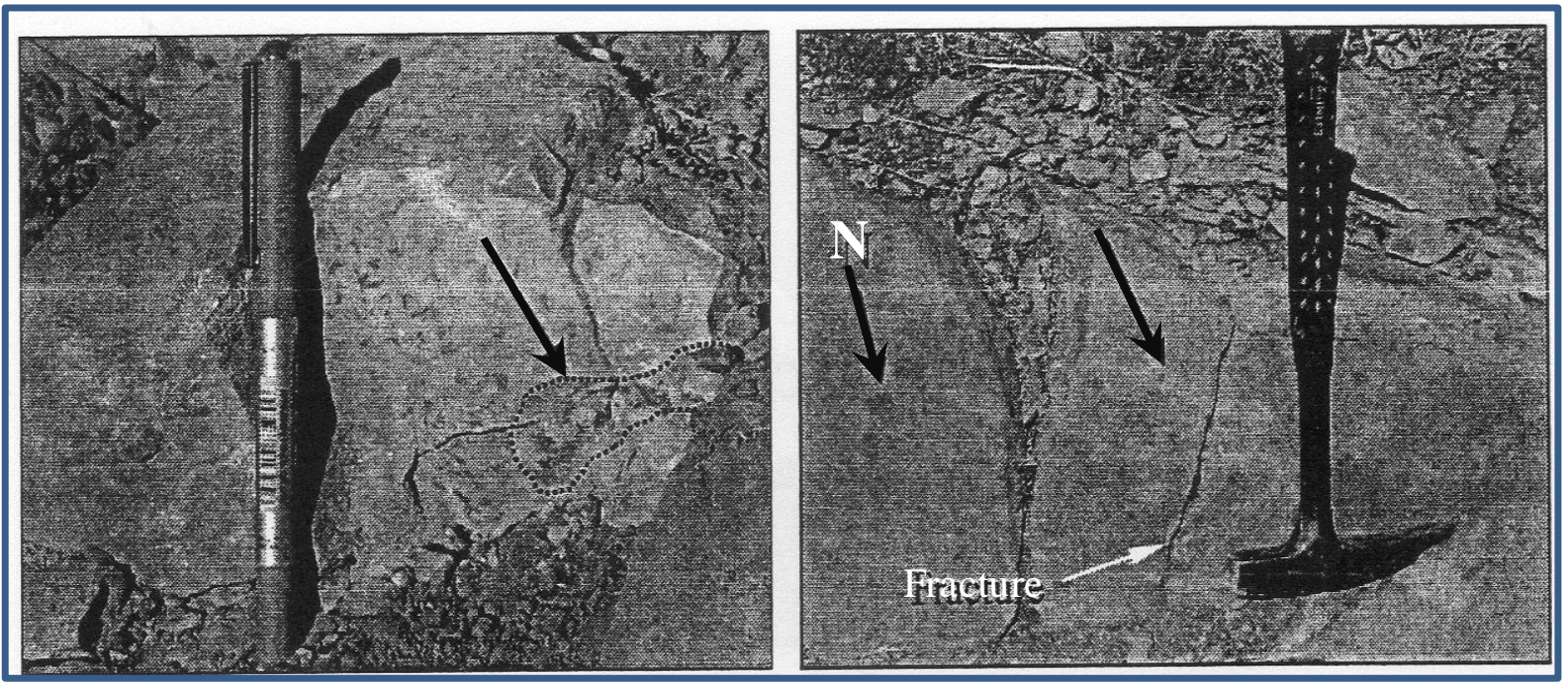

الثكل 8: ثقوب الاحياء ذات الاشكال الاسطوانية والنهايات الثكل 7: حفر الاحياء السهم للمستحثات الاثارية

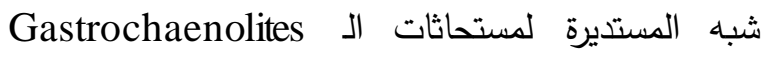
(N) والتراكيب العقدية الداكنة (Thalassinoides)

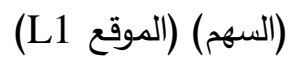

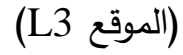




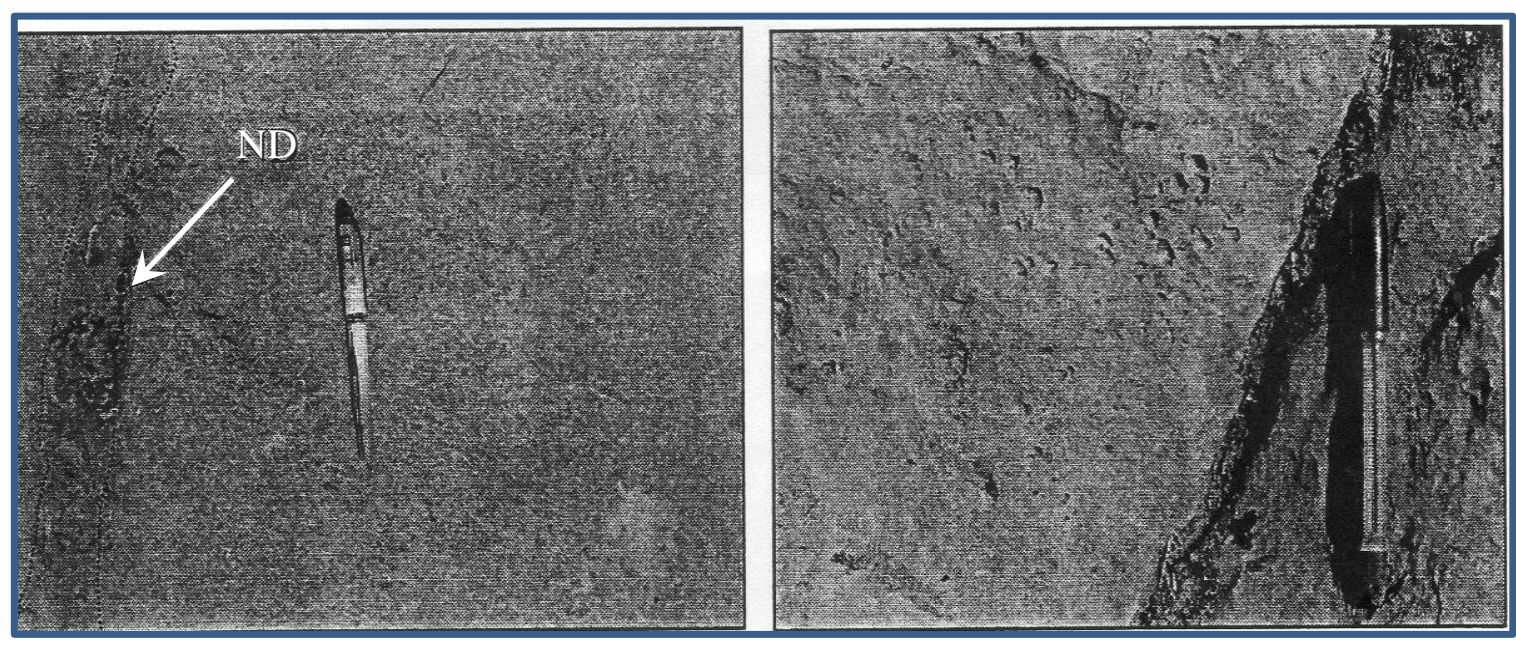

الثكل 10: التراكيب المبقعة على سطح الارض الصلبة

والقاطع النبتوني (ND) (الموقع (L1)
الثكل 9: ثقوب متنوعة على سطح الارض الصلبة يرجح

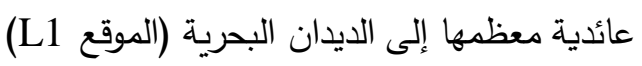

ب - العمليات التحريرية المبكرة (early diagenesis): توفر كيميائية مياه البحر والتجمع المتزايد للاحياء الحارة كالبكتريا والطحالب في رواســب القيعان البحرية الظروف الملائمة لعمليتي المكرّتة والســنتة المبكرة. ويتضــح تأثير فعاليات هذه الأحياء من خلال حفر وتهشيدم

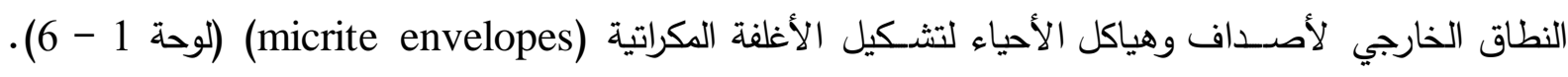
وقد يؤدي استمرار النشاط الطحبي والبكتيري إلى تحطيم هذه الأصداف وامتلاء قوالبها لاحقا بسمنت الكالسدايت

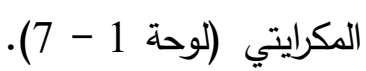

تمثلت مرحلة السمنتة المبكرة لصخور نطاق الأرض الصلبة بوجود ثلاثة أطوار متعاقبة من السمنت تمثلت بالسـمنت المتسـاوي السـمك (isopachous cement) (لوحة 1 - 8) والسـمنت الحافي المتوافق بصديريا (لوحة 2 - 1 1) والسمنت الحبيبي (granular cement) (لوحة 2 - 2). تثدير (syntaxial rim cement) الخصـائص البتروغرافية للسمنت الحبيبي بكونه يمثل الطور الأخير للتصلب المبكر بدليل تسببه في ثلم النهايات

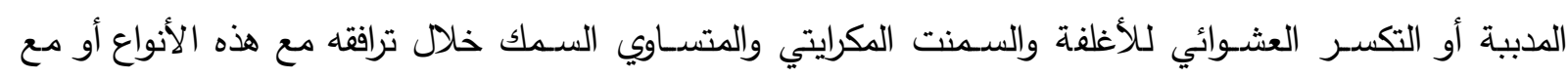
أحدها داخل الفجوات لوحة (2 - 2). تساعد العوامل مجتمعة والمتمثلة بوجود جدران الحفر المتصلبة والمفتوحة وشيوع البكتريا والطحالب وتدفق

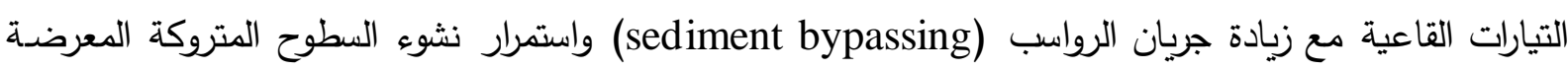

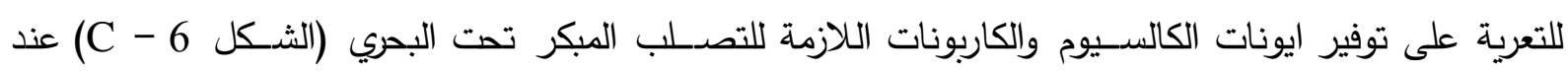
حدود التقاء الترسبات بالمياه البحرية. كذلك يؤدي التصدلب المتعاقب للقيعان الصـخرية في المواقع التي يقل فيها تأثير التعرية الحياتية إلى تكوين سطوح عدم الاستمرارية ذات المقاس المجهري (لوحة 2 - 3)، وهي من الظواهر

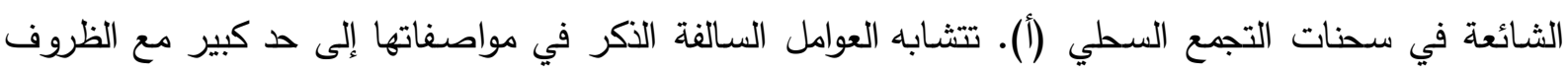

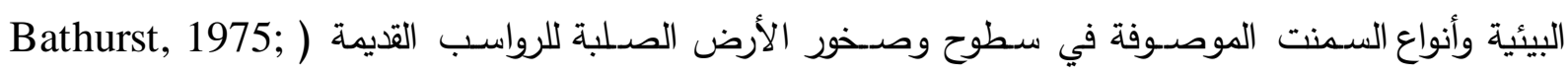
Bathurat, 1975; Whittle et ) وكنلك الحيثة منها (Hips and Haas, 2009; Reolid et al., 2010 


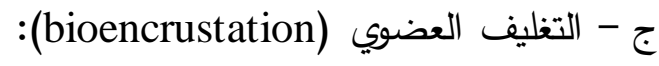
يتمثل التغليف العضدـوي بتراكيب السـتروماتولايت الميكروبي (microbial stromatolite) على هيئة رقائق مستوية إلى قببية الثـكل (laminated to dome-shaped) يكون انتثـارها الجانبي محودا ويتراوح ســمكها بين 20 - 100 مايكرون (لوحة 2 - 4). تحيط هذه الرقائق أحيانا بالحبيبات الكاربوناتية أو المكرايت مكونة حبيبات الأنكويد التي لا تتجاوز أقطارها 1 سـم (لوحة 2 - 1). يؤدي تراكم الســتروماتولايت الميكروبي وحبيبات الأنكويد على أسطح طبقات الأرض الصلبة وبالقرب منها إلى ظهور هذه الأسطح بهيئة قببية أو مضلعة

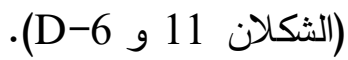

يشير النمو المتقطع لرقائق الستروماتولايت وانتشـاره الجانبي المدود ونشـوء حبيات الإنكويد ووجودهما على أو بالقرب من سطوح الأرض الصـلبة إلى تطورهما ضدمن المراحل المتعاقبة لمواقع التقاء سطح الترسبات بالمياه البحرية. كذلك تدل خصـائص السـنات المكرايتية الحاوية لهذه التراكيب على البيئة البحرية المفتوحة شبه البهاه

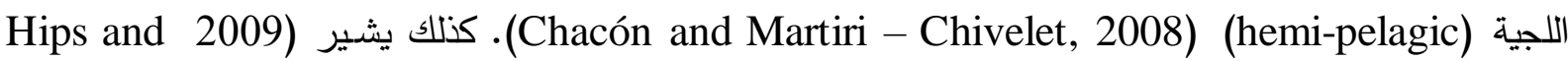
(Haas, المكرايت الميكروبي يحتاج إلى بيئة بحرية مفتوحة ذات طاقة واطئة يقع معظمها ضـــمن المنحدر الكاربوناتي

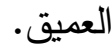

د - التمعدن الثانوي (secondary mineralization): تعد معادن الهيماتايت والجوثايت والليمونات من أهم المعادن الثانوية الموجودة في طبقات الأرض الصـلبة خلال التجمع السحني (أ)، إذ توجد بهيئة عقد شبه مستديرة إلى طولية الشكل يصل قطرها إلى 40 ملم أو بشكل طبقة رقيقة ناتجة عن اندماج العقد مع بعضها البعض وتترتب بصورة موازية لمستوى التطبق (الثكل 12).

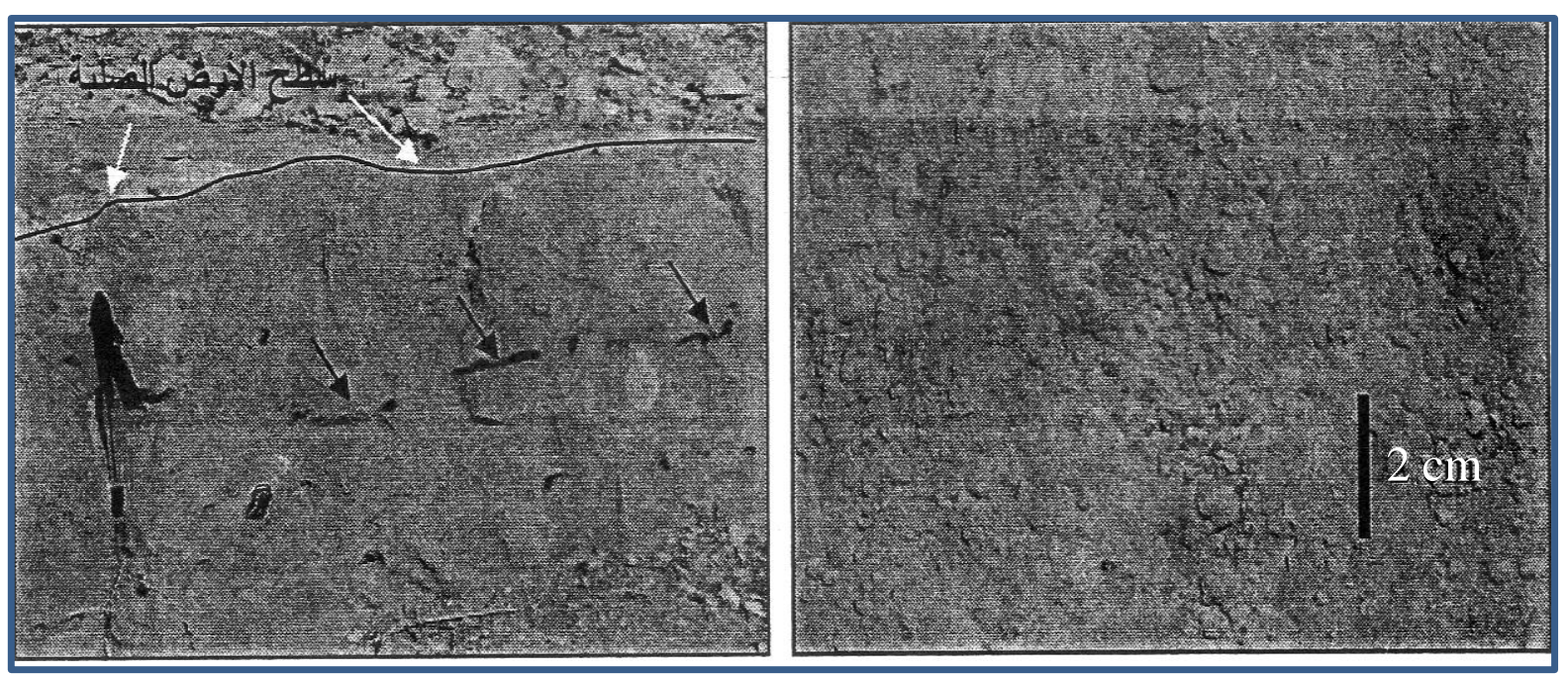

الثكل 11: الستروماتولايت الميكروبي وحبيبات الانكويد الثكل 12: العقد الحديدية (الأسهم) موازية لمستوي التطبق

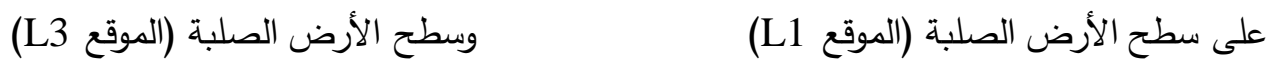

توجد المواد الحيدية أيضـا على هيئة قشور أو صبغات تحيط بالمكونات الصـخرية أو مالئة ومبطنة لحفر وثقوب الأحياء (لوحة 2 - 5). كنلك تتجلى مظاهر التمعدن الأخرى من خلال وجود حبيات ناعمة الحجم غير 
منتظمة الشكل من معدني البايرايت الكلوكونايت منتشرة ضمن الأرضية المكرايتية الناعمة للسحنات الصخرية أو مالئة للفجوات وحفر الأحياء (لوحة 2 - 6 و7) و (الثكل 6 - E). يشدير التراكم المتكرر للمعادن الموضدعية

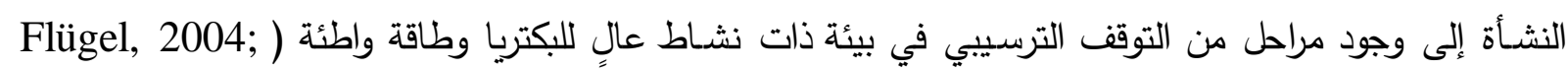
.(Reolid et al., 2010; Clari et al., 1995 هـ العمليات التحريرية المتأخرة (late diagenesis):

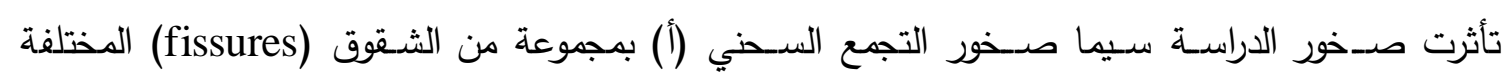
المقياس تراوحت بين العروق المجهريـة (veins) الحادة (لوحة 1 - 1 و 6) و (لوحة 2 - 1 1) إلى الكســور (العمودية وشبه العمودية القاطعة لمكونات الصدخور واثارها الحياتية (الشكل 7) (cracks)

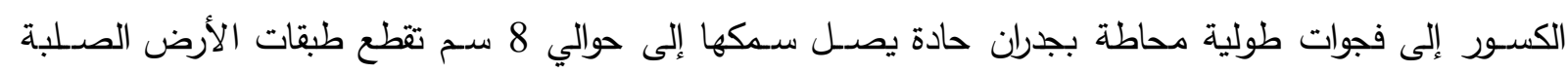
وتصدل إلى أسطحها العلوية لتكوين تراكيب القواطع النبتونية (neptunian dykes)، وتمتلى هذه القواطع لاحقا

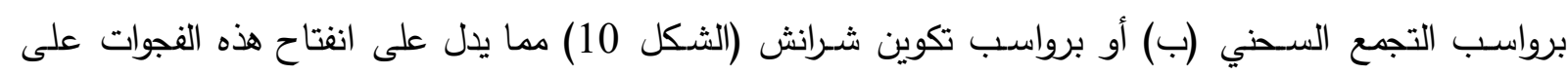

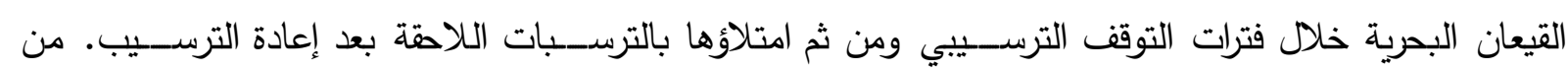
المظاهر الأخرى للعمليات التحويرية المتأخرة تكوين محاليل الضديفط والإذابة لتثــكيل تراكيب الســتايلولايت (stylolites)، والتي قد يؤدي شيوعها أحيانا إلى تكوين التراكيب العقدية أو البريشيا (لوحة 2 - 8) و (الثـكل

يعد وجود القواطع النبتونية وتراكيب الستروماتولايت في طبقات الأرض الصلبة من أحد الأدلة على التوقف الترسيبي تحت البحري (Clari et al.,1995). كذلك تدل هذه الظواهر (تكوين الكسور والقواطع النبتونية) على ونى النشاط التكتوني المتزامن أو اللاحق لعملية الترسيب (Reolid et al., 2010). 3- مرطة ترسيب الرواسب اللجية العميقة (deep pelagic sedimentation): تترسب الرواسب العميقة بعد هدوء تأثير التيارات البحرية أو بسبب الزيادة التدريجية لعمق الحوض الرسوبي

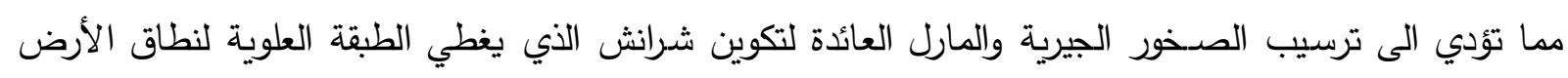

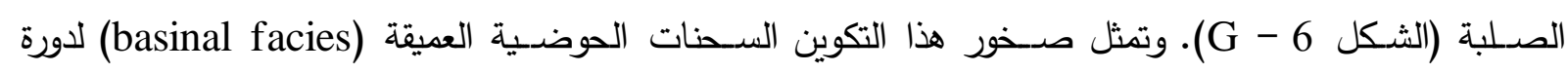
ترسيب فترة الكامبانيان - الماسترختيان في شمالي العراق (Al - Qayim, 1992).

\section{المناقثة}

شـه العصدر الكريتاسي في العراق ظروف انضـغاط تكتوني (tectonic compression) بسبب انفتاح

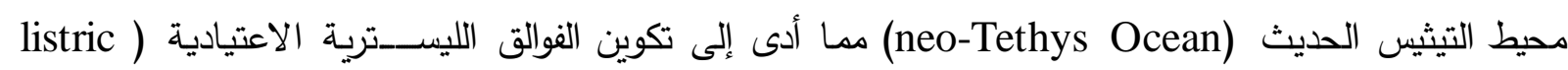

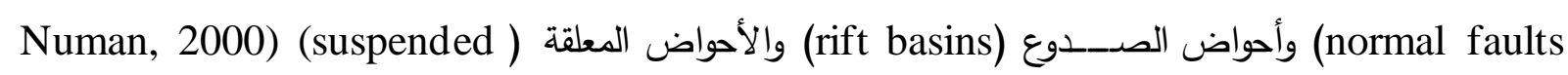
basins)، إذ تميزت فترة الكامبانيان المتأخر في شمالي العراق بالتجلسـات الموضدعية (local subsidence) (Sharland et al., 2001)، واقترحت الثريدة (2009) في دراستها لتكوين بخمة في منطقة دهوك موديل بيئة المنحدر الكاربوناتي (carbonate slope) الناتج عن فالق تحت بحري مزامن للترســيب ليكون ممثلا للعوامل 
ترجح الدراســة الحالية احتمالية تأثر حواف الأرصدفة القارية لفترة الكامبانيان المتأخر في شـمالي العراق بفالق أو عدة فوالق متزامنة مع الترسيب ادت بدورها إلى تجزئة وتقطع هذه الأرصدفة لتكوين كتلة أو سلسلة من الكتل الهابطة والتي ربما تكون منطقة الدراسة ممثلة لإحداها. تشدير الخصـائص الصدخرية والبتروغرافية لرواسب نطاق الأرض الصـلبة إلى اعتبار المنزلق الكاربوناتي ممثلا لتلك الكتلة الهابطة بفعل الانغمار التكتوني، يعد السمك العالي للرواسب الضدطة لسحنات التجمع (أ) في منطقة وادي كرماوة (الموقع L1) مقارنة بسـمكها القليل في مواقع جناحي طية بيخير (الموقعين L2 و L3) اللذان يزداد فيها سمك الرواسب العميقة لسحنات التجمع (ب)، فضـلا عن زيادة نسبة الثقوق والقواطع النبتونية ووجود طبقة المدملكات داخلية المنشـأ ذات الددود السفلية المتموجة وزيادة نسبة مستحاثات المنخربات الطافية واختلاطها بمسـتحاثات أخرى منقولة ومكسـرة باتجاه سـحنات مقطعي جناحي الطية دليلا على تأثير النشـاط التكتوني وانحدار السطح الترسيبي وتعدقه بهذه الاتجاه (شرق وجنوب شرق منطقة الدراسة) (الثكل 13). إن التعاقب العمودي والجانبي لصـخور التجمعين السحنيين (أ) و (ب) وتعاقب السحنات الرسوبية العائدة لكل منهما والدالة على التتعم الحجمي والتعمق باتجاه اعلى التجمعين تشير جميعها إلى تعرض الحوض الرسوبي

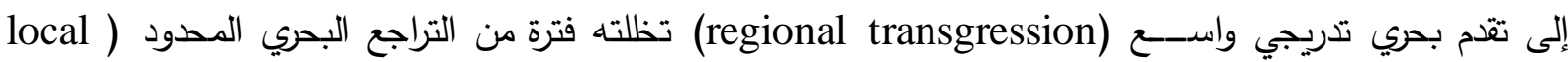
regression ). وخلال ذلك حصدلت العديد من عمليات الترسيب والنقل واعادة الترسيب والتعرية تحت البحرية، ولم تتمكن الرواسب من التواصل المستمر مع الارتفاع النسبي لمستوى سطح البحر مما يثير إلى انخفاض معدل الترسيب الكاربوناتي ومن ثم إلى تكوين سطحين من الأرض الصلبة. تسـبب الهبوط والتقدم البحري التدريجي بزيادة عمق الحوض الرسـوبي وأصــبحت معظم أجزاء المنزلق الكاربوناتي واقعة تحت ظروف البيئة العميقة نسبياً مما أدى إلى ترسيب سحنات التجمع (ب) فوق سحنات التجمع (أ) وتكوين السـطح السـفلي للأرض الصـلبة بينهما، ولقد اسـتمرت هذه الظروف لحين انخفاض مستوى التقدم البحري وبداية التراجع البحري المحدو. إن الانخفاض النسببي لمستوى سـح البحر مهد السبيل لزيادة الإنتاج الكاربوناتي (carbonate factory) في المواقع الضطة للمنزلق وفي إعادة ترسيب سحنات التجمع (أ)، وساعدت لتحني عوامل انخفاض السـعة الاسـتيعابية (accommodation space) للحوض الرسـوبي والانحدار العالي لسـطح الترسيب على تقدم هذه السحنات باتجاه المواقع العميقة للمنزلق لتغطي بذلك رواسب التجمع (ب) السابقة لها ومن ثم تكوين السطح العلوي للأرض الصلبة ، أما ترسيب الرواسب اللجية العميقة لتكوين شرانش فوق رواسب نطاق الأرض الصدلبة فيدل على تعرض الحوض الرسوبي ثانية إلى هبوط تكتوني سربع رافقه ارتفاع واضدح لمستوى سطح البحر مما تسبب في تحول بيئة المنزلق إلى البيئة البحرية العميقة (الثكل 13). 


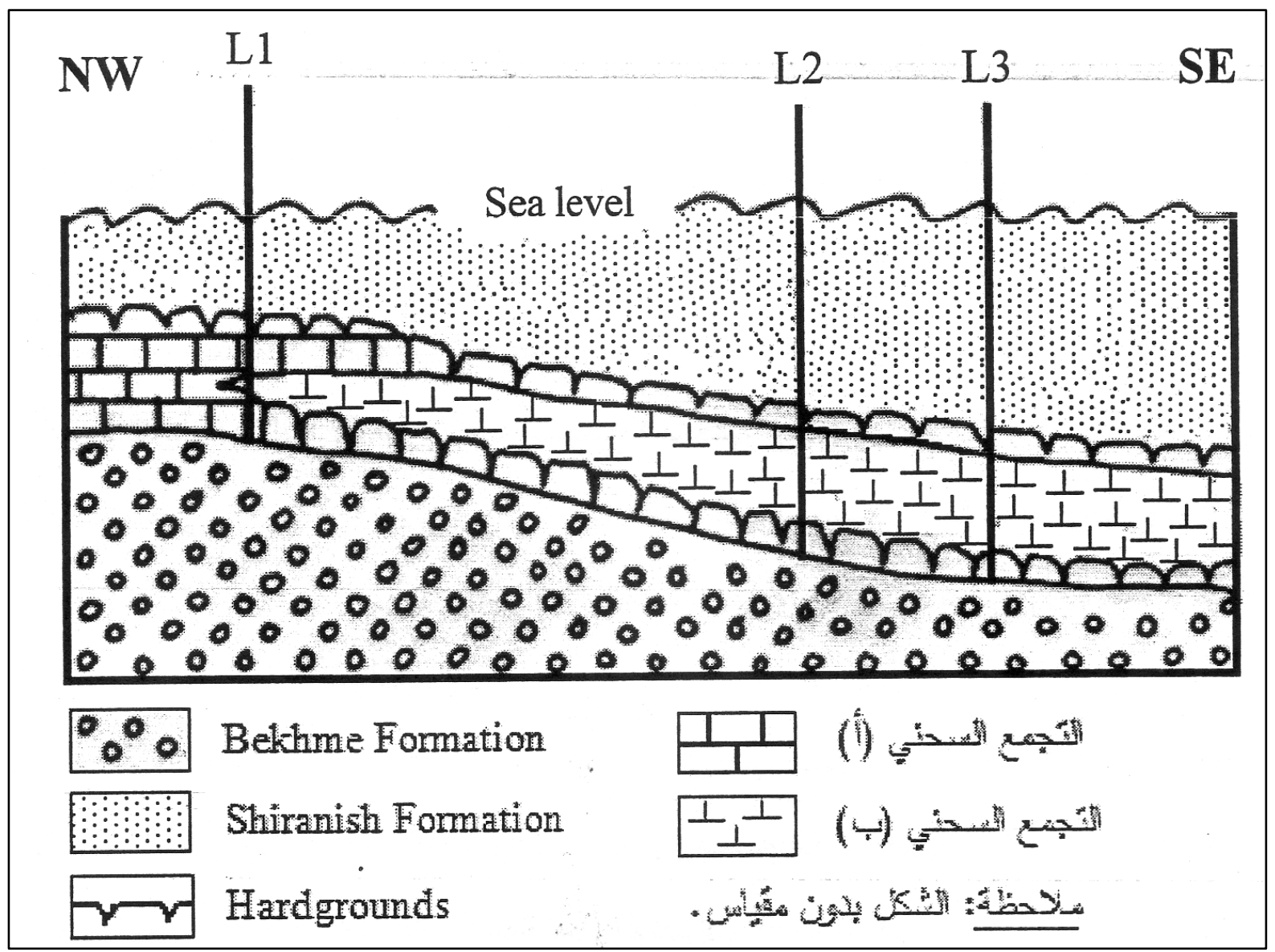

الثكل 13: بيئة المنزلق الكاربوناتي لصخور نطاق الأرض الصلبة بعد الانغمار التكتوني والتعرض لعمليات التقدم والتراجع البحري موضحا فيها مواقع مقاطع الدراسة الثلاثة (L1, L2 and L3).

وتبعا لما اتصفت به رواسب نطاق الأرض الصلبة والأحداث الرسوبية والتكتونية التي مرت بها يمكن القول

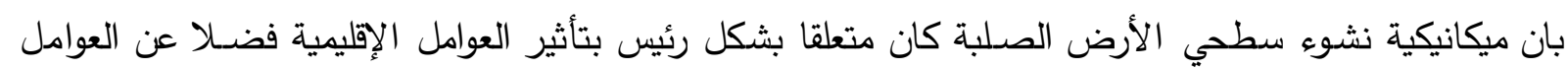

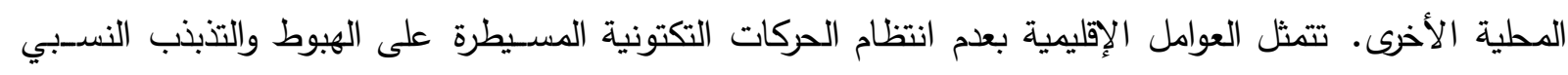

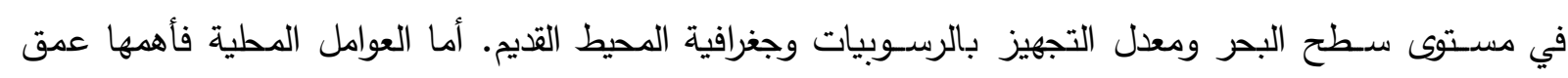
ألحت الموجي (wave abrasion depth) المرتبط بمسـتوى قاعدة الأمواج البحرية (wave base) المحددة

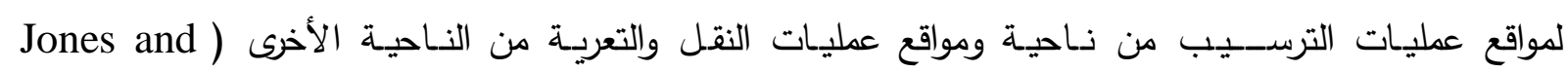
.(Desrochers, 1992 تشير معطيات الدراسة الحالية إلى إمكانية اعتبار رواسب نطاق الأرض الصلبة ممثلا للحالة الانتقالية من

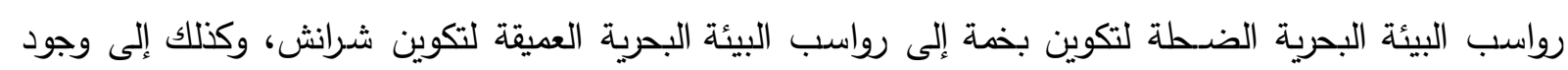
فترة انقطاع وتوقف ترســيبي وحدوث عدم توافق انغماري (drowning unconformity) بين التكوينين خلال الفترة المحصـورة بين الكامبانيان والماسترختيان (Campanian- Maastrichtian boundary)، إلا أن تحديد مرتبة هذا الانقطاع ومدته الزمنية المفقودة تحتاج إلى دراسات دقيقة للطباقية الحياتية مرتبطة بالاعتبارات التكتونية تتجاوز منطقة الدراسة الحالية لتشمل مناطق مختلفة من شمالي العراق. 


\section{الاستنتاجات}

صـنفت صـخور نطاق الأرض الصـلبة إلى تجمعين سـحنيين هما التجمع السحني (أ) والتجمع السحني (ب)، يعد التجمع السـحني (أ) ممثلا لطبقات الأرض الصـلبة وسطوحها، ويتألف بصـورة رئيسـة من الصدخور الجيرية بحجم الرمل الغنية بالمستحاثات ونسبة قليلة من المدملكات الكاربوناتية داخلية المنشا، بينما يتألف التجمع السـني (ب) من الصــخور الجيرية بحجم الرمل والطين والصـخور الجيرية المارلية والمارل. دلت الخصـائص الصـخرية والبتروغرافية لهذين التجعين (أ) و (ب) على ترسيبها في بيئة المنزلق الكاربوناتي الداخلي والأوسـط لئ وبيئة المنزلق الكاربوناتي الخارجي على التوالي. شخصـت ثلاثة مراحل لنشوء وتطور نطاق الأرض الصـلبة، إذ بدأت المرطة الأولى مع انتهاء الترسيب الكاربوناتي الضــل لرواسـب تكوين بخمة نتيجة الهبوط التكتوني للأرصدفة القارية وانغمارها. وضـمت المرحلة الثانية سلسدلة من الأحداث الرسـوبية والحياتية المتعاقبة أو المتداخلة التي سـاهمت في نشـوء وتطور سطحي الأرض الصــلبة متمثلة بمظاهر الحفر والتثقيب الحياتي وعمليات المكرتة والسـمنتة المبكرة والتغليف العضــوي

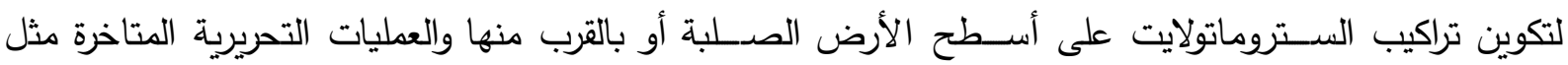
الثقوق والقواطع النبتونية وتراكيب الستايلولايت. وتختتم هذه العمليات بالمرطة الثالثة التي تترسب خلالها رواسب تكوين شرانش العميقة فوق طبقات نطاق الأرض الصلبة. تمثل منطقة الدراسة واحدة من كتل الأرصفة القارية الهابطة بفعل الفوالق المتزامنة مع الترسيب خلال فترة الكامبانيان التي شهحت ظروفا تكتونية غير مسـتقرة، ويعد المنزلق الكاربوناتي ممثلا لتلك الكتلة الهابطة. أشـار التعاقب العمودي والجانبي للتجمعين السحنيين (أ) و (ب) وتعاقب السحنات التابعة لكل منهما إلى تعمق وانحدار المنزلق الكاربوناتي باتجاه جناحي طية بيخير المدبة، وتعرضـه إلى تقدم بحري تدريجي واسع تخلله تراجع بحري

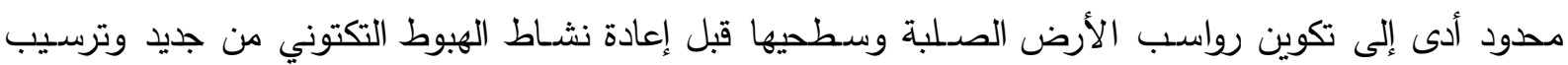
الرواسب اللجية لتكوين شرانش، وعليه يعد نطاق الأرض الصدلبة ممثلا لفترة توقف ترسيبي وعدم توافق انغماري ما بين تكويني بخمة وشرانش.

\section{المصادر العربية}

الثـريدة، وئام مزاحم عبد الواحد، 2009. دراسـة التغايرات الرسوبية لتكوين بخمة في مكثـف محدد من منطقة دهوك شمال العراق. رسالة ماجستير غير منشورة، جامعة الموصل، العراق، 112 صفحة.

\section{المصادر الأجنبية}

Al-Mutwali, M.M., Al-Banna, N.Y. and Al-Ghrear, J.S., 2008. Microfacies and sequence stratigraphy of the Late Campanian Bekhme Formation in the Dohuk area, north Iraq. GeoArabia, Gulf PetroLink, Bahrain, Vol. 13, No. 1, pp. 39-53.

Al-Qayim, B., 1992. Bioturbated rhythmite of the Shiranish Formation, Type locality, NW Iraq. Iraqi Geol. Jour., Vol. 25, No. 1, pp. 185-194.

Bádenas, B. and Aurell, M., 2001. Proximal-distal facies relationship and sedimentary processes (Kimmeridgian, northwest of the Iberian Ranges, Spain). Sed. Geol., Vol. 139, pp. 319-342. 
Bádenas, B. and Aurell, M. and Cröcke, D.R., 2005. Facies analysis and correlation of high-order sequences in middle-outer ramp successions: variation in exported carbonate on basin-wide 8 NE Spain). Sedimentology, Vol. 52, pp. 1253-1275.

Bathurst, R.G.C., 1975. Carbonate Sediments and their Diagenesis, 2nd ed. Development in Sedimentology 12, Elsevier Publ. Comp., Amsterdam, 658p.

Bellen, R.C. van; Dunnington, H.V.; Wetzel, R. and Morton, D.M., 1959. Lexique Stratigraphique International, Asie, Fasc. 10a, Iraq. Centre Natl. Rech. Scii, Paris, $333 p$.

Bromley, R.G., 1975. Trace fossils at omission surfaces. In: The Study of Trace Fossils (Ed. R.W. Frey), pp. 399-428, Springer-Verlag, New York.

Burchette, T.P. and Wright, V.P., 1992. Carbonate ramp depositional systems. Sed. Geol., Vol. 79, pp. 3-57.

Chacón, B. and Martin-Chivelet, J., 2008. Stratigraphy of Paleocene phosphate pelagic stromatolites (Prebetic zone, SE Spain). Facies, Vol. 54, pp. 361- 376.

Clari, P.A., Pierre, F.D. and Martire, L., 1995. Discontinuities in carbonate successions: identification, interpretation and classification of some Italian examples. Sed. Geol., Vol. 100, pp. 97-121.

Dickson, J.A.D., 1966. Carbonate identification and genesis as revealed by staining. Jour. Sed. Petrology, Vol. 36, pp. 491-505.

Flügel, E., 2004. Microfacies of Carbonate Rocks: Analysis, Interpretation and Application. Springer-Verlag, Berlin, 976p.

Folk, R.L., 1962. Spectral subdivision of limestone types. In: Classification of Carbonate Rocks (Ed. W.E. Ham), AAPG. Mem., 1, pp. 62-84.

Gómez-Pérez, I., Fernández-Mendiola, P.A. and Garcia-Mondéjar, J., 1998. Constructional dynamics for a Lower Cretaceous carbonate ramp (Gorbea Massif, north Iberia). In: Carbonate Ramps (Eds V.P. Wright and T.P. Burchette), Geol. Soc. London Spec. Pub., Vol.149, pp. 229-252

Grádinaru, M., Lazár, I. and Panaiotu, C.E., 2011. Preliminary report on the microfacies analysis of the hardgrounds and condensed horizons associated to the Middle Jurassic deposits from Tátarului Gorges (Bucegi Mountains, SE Carpathians). Acta Palaeo. Romaniae, Vol. 7, pp. 169-175.

Hips, K. and Haas, J., 2009. Triassic boundary interval and basal Triassic carbonates: shallow and deep ramp sections, Hungary. Facies, Vol. 55, pp. 421-442.

Jones, B. and Desrochers, A., 1992. Shallow platform carbonates. In: Facies- models Response to sea level change (Eds R.G. Walker and N.P. James), Geol. Assoc. Canada, pp. 407-454.

Kreisa, R.D., 1981. Storm-generated sedimentary structures in subtidal marine facies with examples from the Middle and Upper Ordovician of southern Virginia. Jour. Sed. Petrology, Vol. 51, pp. 823-848.

Numan, N.M.S., 2000. Major Cretaceous tectonic events in Iraq. Raf. Jour. Sci., Vol. 11, No. 3, pp. 32-52. 
صخارية ومراحل نشأة نطاق الارض الصلبة في اعلى الجزء العلوي لتكوين بخمة، منطقة دهوك، شمالي العراق

Pomar, L., 2001. Types of carbonate platforms: a genetic approach. Basin Research, Vol. 13, pp. 313-334.

Read, J.F., 1985. Carbonate platform facies models. AAPG Bull., Vol. 69, No. 1, pp. 121.

Reolid, M., Nieto, L.M. and Rey, J., 2010. Taphonomy of cephalopod assemblages from Middle Jurassic hardgrounds of pelagic swells (South- and diagenetic evaluation of the Permian- Iberian Palaeomargin, Western Tethys). Palaeogeography Palaeoclimatology Palaeoecology, Vol. 292, pp. 257-271.

Sharland, P.R., Archer, R., Casey, D.M., Davies, R.B., Hall, S.H., Heward, A.P., Horbury, A.D. and Simmons, M.D., 2001. Arabian Plate Sequence Stratigraphy. GeoArabia, Spec. Publ. 2, Gulf PetroLink, Oriental Press, Manama, Bahrain, 371p.

Whittle, G.L., Alsharhan, A.S. and Kendall, C.G.St.C., 1998. Petrography of Holocene beach rock and hardgrounds, Abu Dhabi, United Arab Emirates. In: Quaternary Desert and Climatic Change (Eds A.S. Alsharhan, K.W. Glennie, G.L. Whittle and C.G.St.C. Kendall), pp. 57-68. A.A. Balkema, Rotterdam.

Winterer, E.L. and Bosellini, A., 1981. Subsidence and sedimentation on a Jurassic passive continental margin, Southern Alps, Italy. AAPG Bull., Vol. 65, pp 394421. 
(لوحة 1 (لومان
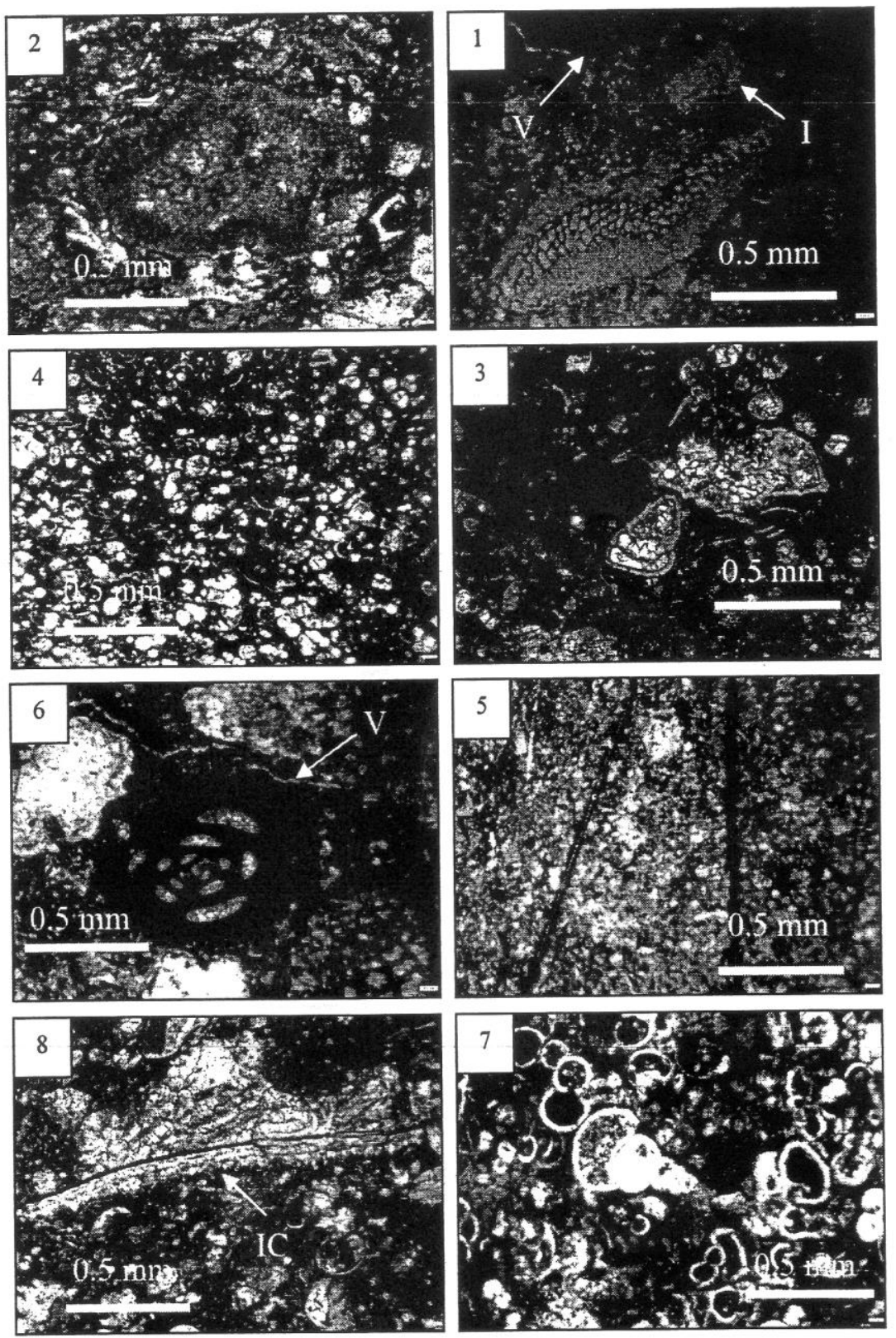

1 ـ المنخربات القاعية الكبيرة (orbitoids) في ســحنة المكرايت الأحاثي المتفرق (ت س ـ أ) مع وجود الفتات الداخلي (1) والعروق (7) (الموقع L1). 2- الانكويد في سـحنة المكرايت شحيح المستحاثات (ت م ـ أ) وتأثر غلافها الخارجي بعمليات الحت والنقل (الموقع L2). 3- سـحنة المكرايت المتفرق الحاملة للمنخريات الطافية وبعض النواعم صغيرة الحجم (ت س . ب) (الموقع L2). 4-حشود متكدسة من المنخربات الطافية (ت سب) (الموقعL3). 5- الثقوب الحياتية العمودية وشبه العمودية في مطة المكرايت شحيح المستحاثات

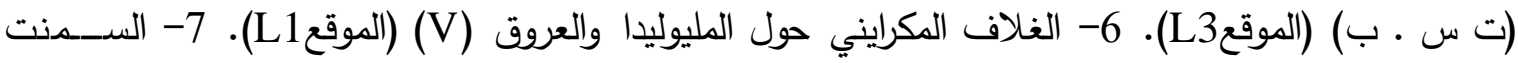
المكرايتي المالئ القوالب المستحاثات (الموقع L3)، 8- السمنت المتساوي السمك يحيط بقطعة من أصداف رأسية القدم (IC) (الموقع L2). ملاحظة : جميع الصور مأخوذة تمت المستقطبين المتعامدين. 


\section{(لوحة 2)}
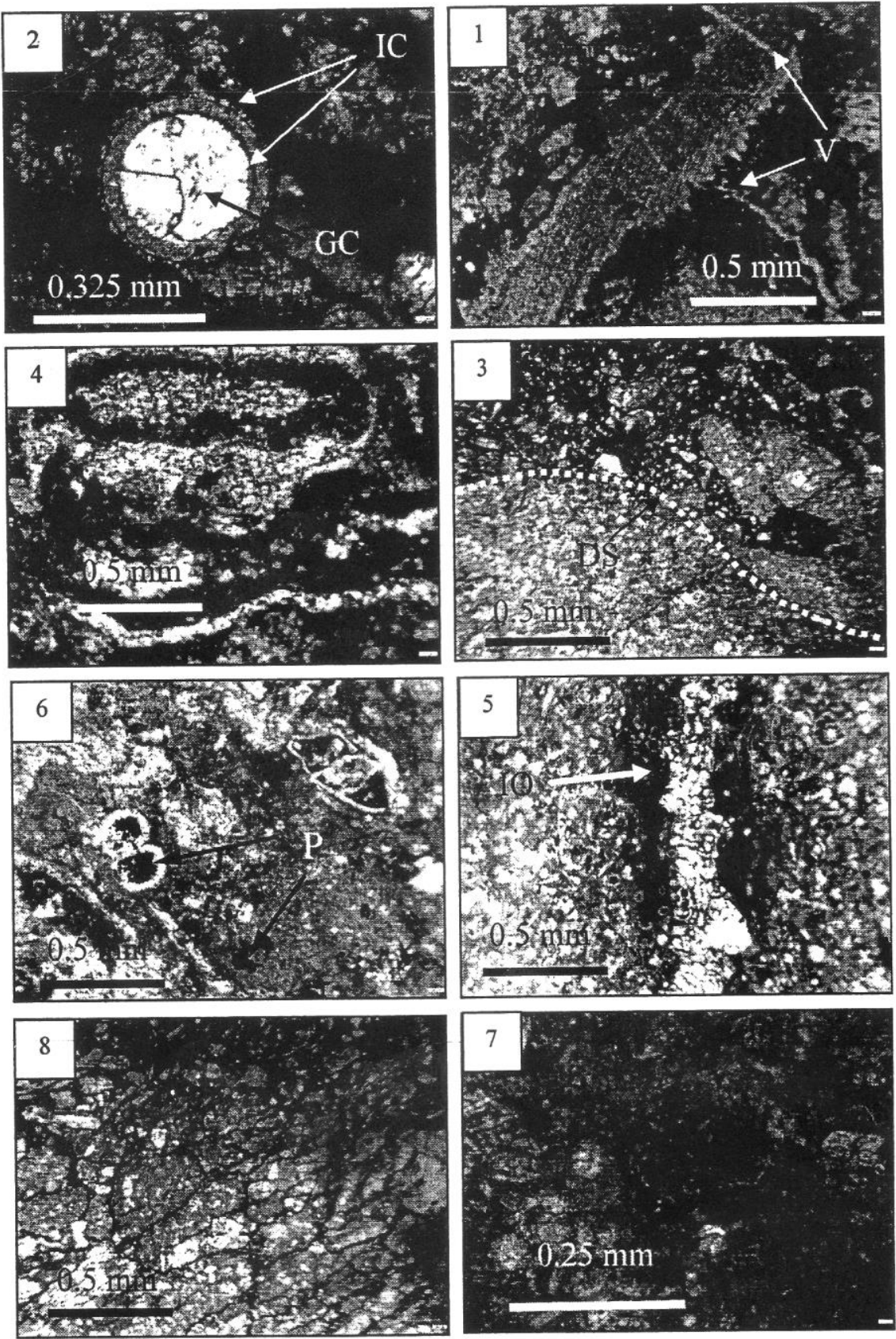

1 ـ السمنت الحافي المتوافق بصسريا يحيط بقطعة من شوكية الجلد والعروق القاطعة لها (V) (الموقعاL1). 2السـمنت المتسـاوي السمك (IC) داخل وخارج القالب المنخربات الطافية والسمنت الحبيبي (GC) اللاحق داخل القالب (الموقع2L2). 3- سـطح عدم الاســتمرارية (DS) بين ســحنتي المكرابت الأحاثي المتفرق والمكرابت شـحيح المسـتحاثات (الموقعL3). 4- الســترومايت الميكروبي ذي الهيئة المســتوية والقببية

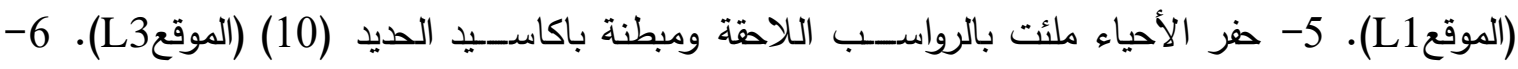
البايرايت داخل قوالب المنخربات الطافية ومنتشـرة في أرضدية الصدـخرة (الموقع2L2). 7- الكلاكونايت في أرضــية الصدخرة (الموقع2L). 8- التراكيب العقدية الناتجة عن الســايلولايت المتشـابك (الموقع L2) . ملاحظة : جميع الصور مأخوذة تصت المستقطبين المتعامدين. 